\title{
Observing soil biota in situ
}

\author{
John Lussenhop ${ }^{\mathrm{a}}$ and Robert Fogel ${ }^{\mathrm{b}}$ \\ appartment of Biological Sciences, The University of Illinois at Chicago, Box 4348, Chicago, IL \\ 60680, USA \\ ${ }^{b}$ Herbarium, University of Michigan, Ann Arbor, MI 48109, USA
}

(Received November 28, 1991; accepted after revision March 4, 1992)

\begin{abstract}
Lussenhop, J. and Fogel, R., 1993. Observing soil biota in situ. In: L. Brussaard and M.J. Kooistra (Editors), Int. Workshop on Methods of Research on Soil Structure/Soil Biota Interrelationships. Geoderma, 56: 25-36.

Rhizotrons and minirhizotrons allow repetitive, nondestructive observation of the soil biota. Bias associated with minirhizotron and rhizotron observations, and methods that will help realize the potential of these observational platforms are reviewed. Root density estimates in minirhizotrons are prone to bias due to soil compaction, and poor contact between tube and soil. Density estimates of microarthropods observed in minirhizotrons, are less biased by longer observation periods, low light levels, and good optical resolution. Microarthropods observed in a rhizotron were underrepresented compared with soil cores if they belonged to groups that move little, are transparent, or small. Timelapse video can be used to sample microarthropod density in rhizotrons. Better visualization of all of the biota can be achieved by using long working length microscope objectives, and stains such as fluorescein diacetate, ethidium bromide and the tetrazolium dye, p-Iodonitrotetrazolium Violet. Repeated observation of the same roots allows the use of demographic methods for calculation of root survivorship, turnover, and productivity.
\end{abstract}

\section{INTRODUCTION}

Minirhizotrons and rhizotrons are revolutionizing soil biology by making it possible to nondestructively observe the soil biota in situ. Root growth and physiology have been studied by direct observation in the six lysimeter type rhizotrons in North America (Huck and Taylor, 1982). During the 1980's opportunities for direct observation of the soil biota increased because of the commercial availability of minirhizotron video cameras starting in 1984 (J.M. Bartz, pers. commun., 1991) the construction of an experimental rhizotron at the University of Michigan Biological Station, and the availability of computer-based image analysis systems.

Correspondence to: J. Lussenhop, Department of Biological Sciences, The University of Illinois at Chicago, Box 4348, Chicago, IL 60680, USA. 
These new observational tools allow the in situ study of spatio-temporal relationships of the entire range of soil biota: roots, microorganisms, protozoa, and invertebrates. Kubiëna (1955) would have made a stronger case for invertebrate control of humus formation if he could have watched the biota colonize earthworm burrows and collembolan faecal pellets rather than relying on soil sections. Similarly, Hole (1981) could have relied less on descriptive soil surveys to make his argument for animal effects on soil structure if he had had access to direct observation.

Minirhizotrons are relatively easy to install, and thus their increasing use for comparative studies in natural habitats should be expected. Exploration of below-ground habitats with minirhizotrons is important because more than half of net primary productivity is below-ground in the five natural communities for which data is available (Caldwell, 1987): root productivity is greater than previously estimated (Long et al., 1989).

Availability of minirhizotrons and experimental rhizotrons focus attention on sources of bias and inaccuracy in the data that can be collected with them as well as on methodology for their use. Sources of the methodology include methods used for data collection aboveground and laboratory methods that can be adapted for use in situ. The purpose of the present paper is to review biases and and new opportunities offered by minirhizotrons and rhizotrons.

ROOTS

\section{Sampling bias}

Minirhizotron tubes or rhizotron windows may cause a number of kinds of bias in estimates of root density. Instillation may either compact the soil around minirhizotron tubes, or leave a space between tube or window and soil. For rhizotrons, reconstruction of the soil profile may affect root density, but Atkinson (1985) found no difference between root density of apple trees next to windows at the East Malling rhizotron and bulk soil. For minirhizotrons, a number of methods are used for minimizing soil compaction during installation, and for keeping good contact between soil and tube (Van Noordwijk et al., 1985). In order to tightly fit the minirhizotron tube in soil with a minimum of campaction, Box et al. (1989) suggested pushing tubes into the ground by applying force on the inside bottom in order to stretch and thin the tube when entering the hole. Gijsman et al. (1991) inserted a metal frame into the ground and inflated a rubber tube in it; observations were made with the tube removed and nothing between the lens and the root surface. Soil compaction led to underestimates of root density in some studies (Cheng et al., 1990). Gijsman et al. (1991) commented on the difficulty of making observations during spring and fall due to condensation on the inside of plastic minirhizotron tubes. Observed root density should be compared with density 
from core samples for both rhizotrons and minirhizotrons. Vos and Groenwold (1987) suggested that conversion factors based on root density in soil cores be used for minirhizotron data. In spite of the methodology just reviewed, biases caused by instillation of minirhizotrons and rhizotrons in highly structured soil have not been assessed with a variety of methods.

A potential source of bias for rhizotrons is extensive flat surfaces which may make root systems atypical, or change their phenology. Atkinson (1985) showed that root systems of apple trees around the East Malling rhizotron were not atypical in shape or phenology. Further he pointed out that the volume of soil that can be sampled at rhizotron windows may be as great as that in cores, and sampling windows requires less work. The great observational area in rhizotrons allows study of the biological basis of spatial variability of roots.

Minirhizotrons can be installed among crops or in natural communities receiving experimental treatments, and, experimental manipulation next to minirhizotron tubes is possible also. For example, Rush et al. (1984) placed sclerotia of Phymatotrichum omnivorum on minirhizotron tubes and allowed cotton seedling roots to grow over them, permitting investigators to photograph mycelial strands proliferating from infected roots. Nutrients or inoculum could be added to the surface of minirhizotron tubes through cannulae. In rhizotrons manipulations may be applied by removing and replacing windows, or by adding materials through holes drilled through them. Experimental manipulations that might be applied to small soil volumes next to minirhizotrons or behind windows include release of $\mathrm{CO}_{2}$, and addition of known fungal or bacterial inoculum, invertebrates, microspheres, dyes, or small amounts of nutrients. Removal experiments that might be conducted include removal of roots belonging to particular species, clipping or freezing of roots to simulate herbivory, and reduction of invertebrate populations with biocide application.

\section{Root density and productivity}

Minirhizotrons have been used to contrast response of roots to different tillage (Cheng et al., 1990), crop (Hansson and Andren, 1987), and community types (Aerts et al., 1989). These studies took advantage of the ease of locating minirhizotrons in the field, but did not take advantage of the opportunity to follow development of individual roots.

The ability to observe nondestructively makes it possible to record development of individual roots of known age in minirhizotrons and rhizotrons. Such data allows application of demographic methods to roots for the first time. Demographic methods are especially helpful in quantifying root turnover and productivity. For example, if a cohort of roots that are the same age is followed through their developmental stages-white, brown, missing, dead- 
the age-specific probabilities of entering the next stage or dying can be tabulated and used to calculate survivorship, productivity, and turnover. This is comparable to the cohort life table approach. A second approach, comparable to a static life table, is to start with a population of roots of unknown ages and record developmental changes. These records for individual roots may be used to calculate the probability of the average root going to the next stage, and will give the same estimates of survival, production, and turnover as the cohort approach if there is no long-term environmental change and no change in root density. Hendrick and Pregitzer (1992) made this kind of analysis for roots of a hardwood forest in northern lower Michigan during one year. They summarized changes from white to brown to dead roots in a table of transition probabilities for intervals between each sampling date.

Root productivity measured by recording simultaneous growth and death of cohorts of roots is more accurate than summing statistically significant increases in root biomass plus significant increments in dead root biomass between sampling times. Hendrick and Pregitzer (1992) found a 54\% (top 30 $\mathrm{cm}$ ) and 46\% (30-60 cm) higher, and Cheng et al. (1990) a 40\% higher root productivity than if they had summed growth and mortality increments. Further, Hendrick and Pregitzer (1992) noted that 95\% of the roots disappeared before they were in the dead category. This evidence of rapid decomposition and/or herbivory would have been missed if individual roots had not been followed.

\section{Aids to visualizing roots}

Infrared lighting emphasizes contrasts. Dark roots, roots of legumes, cereals, and native grasses are easier to see with UV light. Other ways to visually emphasize roots and their activity include adapting laboratory methods for use in rhizotrons. For example, fluorescein diacetate (FDA) was used by Söderström (1977) to distinguish living from dead fungal hyphae in laboratory preparations. FDA is hydrolyzed to free fluorescein by many enzymes, hence fluorescein is a good indicator of viability. In rhizotrons with removable windows, FDA may be sprayed on soil faces causing metabolically active roots and other biota to fluoresce in situ. Ethidium bromide (EB) is another fluorescent dye that can be used to visualize metabolic activity in eucaryotic cells because it binds with DNA and RNA. Roser (1980) showed that EB stained nuclei of active root, fungal, and bacterial cells. EB could be sprayed on soil in aqueous solution and observed with appropriate filters although, because of its toxicity, EB could not be used repeatedly.

\section{Microorganisms}

Macroscopic fungal structures may be counted in rhizotrons and minirhizotrons allowing density estimates of ectomycorrhizae, rhizomorphs, and col- 
onies of saprophytic fungi. Periodic observations of the same ectomycorrhizae, and saprophytic fungal colonies allow determination of age-specific survivorship and of productivity using life table methods. Even simple records of growth may be useful when they are related to other biota. In Fig. 1, for example, changes in area of four Coenococcum geophilum ectomycorrhizae are negatively associated with numbers of microarthropods observed in the quadrat $(p<0.01$, Wilcoxon matched-pairs signed-ranks test $)$.

Higher magnifications may be achieved by using long focal length microscope objectives, with the light source off center to enhance contrast (L.E. Casida, pers. commun., 1991). The use of a compound microscope with reflected light to visualize microbes in situ was described by Casida (1969), and confocal microscopes may by useful in this way as well.

Additional laboratory methods that we believe will be useful in rhizotrons are UV light, FDA, and tetrazolium dyes. The length of roots containing vesicular-arbuscular mycorrhizae can be counted non-destructively by using the observation of Ames et al. (1982) that arbuscules in living roots autofluoresce. Application of this method requires use of quartz glass, a concentrated source of UV light, and appropriate filters (e.g. Allen et al., 1989).

FDA is useful in staining active hyphae as well as roots. EB has been used as a counterstain with FDA in laboratory studies of bacteria. EB combines

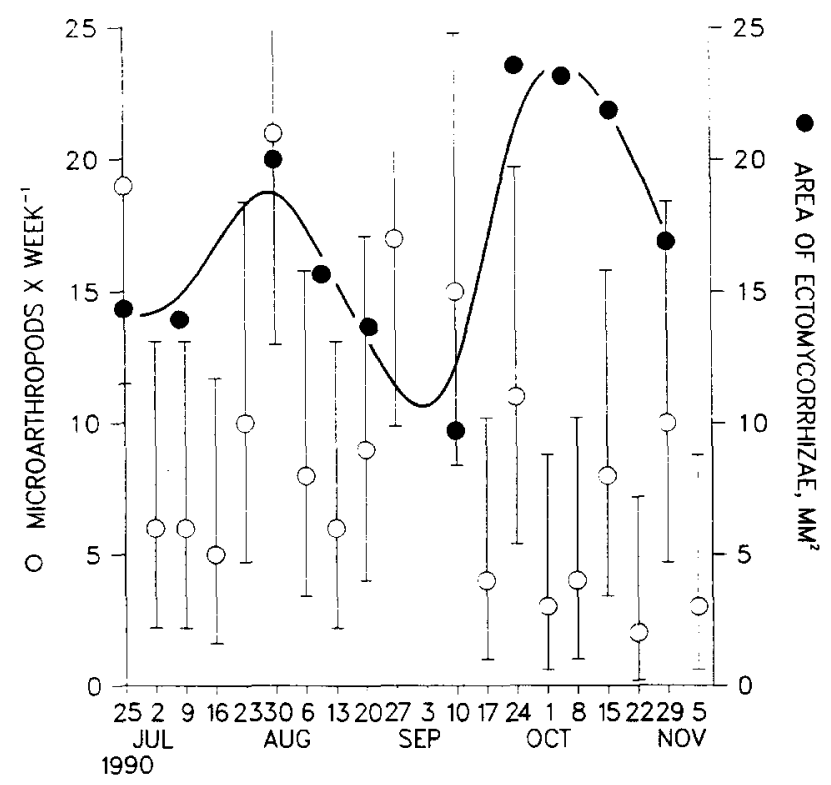

Fig. 1. Total microarthropods observed per week and the area of four Coenococcum geophilum ectomycorrhizae in the same $1 \mathrm{~cm}^{2}$ area. Observations were made with time-lapse video in the University of Michigan Soil Biotron. The heavy lines are three-week running averages. Vertical bars are 5\% Poisson confidence limits around total microarthropods seen per week. 
with DNA regardless of viability, staining non-viable bacteria orange in Jarnagin and Luchsinger's (1980) study, while viable bacteria fluoresced yellowgreen from FDA.

Metabolically active microorganisms reduce the tetrazolium salt $\mathrm{p}$-iodonitrotetrazolium violet (INT). producing formazan particles which are easily visible within cells. These dyes were used to quantify metabolic activity of saprophytic fungi (MacDonald, 1980) and external hyphae of vesicular-arbuscular mycorrhizae (VAM) (Sylvia, 1988). Use of INT in a rhizotron would require spraying a solution of INT, NADH, and buffer on the soil face, and observing formazan with a compound microscope.

\section{INVERTEBRATES}

\section{Sampling bias}

Direct observation of invertebrates in minirhizotrons and rhizotrons is appealing because the methods used to extract invertebrates from soil select mobile, desiccation-resistant species. There is no bias in direct counts of large invertebrates such as earthworms or Scarabaeid beetle larvae in minirhizotrons and rhizotrons unless it is shown that they are affected by plastic or glass surfaces. Carpenter (1988) demonstrated that diplura feed on roots by observation in a rhizotron.

Direct counts of smaller invertebrates such as microarthropods, nematodes, and protozoa, involve biases. Microarthropods will be used to illustrate bias encountered in direct counts using minirhizotrons and rhizotrons.

\section{Minirhizotrons}

Snider et al. (1990) used minirhizotrons to observe collembola around roots of corn (Zea mays), soybeans (Glycine max) and sugarbeets (Beta vulgaris) in Michigan. They showed that (1) more than half of the collembola population moved below $30 \mathrm{~cm}$ after the middle of August in each crop, and (2) collembola density was correlated with change in root number per time. Snider et al. (1990) also showed that resolution was so poor that only larger, moving collembola could be counted. This effectively limited the study to Folsomia candida. They suggested that when invertebrates are filmed in minirhizotrons the camera should be held still long enough so that movements of the animals can be used to aid in identification, the camera focus should be carefully monitored, and condensation on the inside of the tubes in fall and spring should be avoided by filming early or late in the day. Finally, high light levels used in filming in minirhizotrons clearly drives invertebrates away. 


\section{Rhizotrons}

Litter invertebrates can be observed in the rhizotron described by Carpenter et al. (1985) because the windows extend above the soil surface. Windows are recessed in the University of Michigan Soil Biotron described by Fogel and Lussenhop (1991) making it difficult to focus a dissecting microscope on the litter. With this limitation recognized, data collected at the Soil Biotron was used to compare density estimates made by direct counts through the windows with estimates made by counting microarthropods extracted from soil cores collected next to the windows.

Direct counts of microarthropods were made by observing $1.2 \mathrm{~cm} \times 12.5$ $\mathrm{cm}$ strips on the safety glass with a dissecting microscope at 12 to $50 \times$. Microarthropods were counted in an area of $3037 \mathrm{~cm}^{2}$ on August 15, 1989, and an area of $553 \mathrm{~cm}^{2}$ on May 23, 1991 at depths of $2.5,6$, and $9 \mathrm{~cm}$. It is possible to see about $2.5 \mathrm{~mm}$ into the soil, a Rubicon sand; accordingly the area observed was multiplied by $2.5 \mathrm{~mm}$ to estimate density per volume. The total volumes sampled were $759 \mathrm{~cm}^{3}$, and $138 \mathrm{~cm}^{3}$ in August and May.

On the same dates, soil cores were collected $0.5 \mathrm{~m}$ away from alternate windows of the Soil Biotron. The soil cores were $19.17 \mathrm{~cm}$ in diameter and $9 \mathrm{~cm}$ deep. The total volumes of soil sampled with soil cores were 2.7 and 8.3 times greater than the volumes observed in August and May respectively.

After collection, cores were divided into $3 \mathrm{~cm}$ sections, and fitted into holes in a foam rubber mat over crystalizing dishes of picric acid in a high-gradient extraction apparatus (Lussenhop, 1971). Intensity of heat above the cores was increased and temperature of water circulating below was lowered during a six day period, causing the microarthropods to move down through the drying soil and fall into the picric acid. When the soil core sections were dry, the dishes of picric acid were filtered, microarthropods were removed from the filter paper under a dissecting microscope, mounted in Hoyer's medium, and counted under a compound microscope. This type of extraction method was found, in a thorough survey (Edwards and Fletcher, 1971, table IV), to be significantly more efficient for mobile, desiccation-resistant species such as oribatids, than for less mobile, desiccation-susceptible groups such as collembola, and protura.

Movement, color, and size were key factors in recognition of microarthropods in situ. Only prostigmatid mites (August) and protura (May) were observed in statistically greater numbers than in extractions (Fig. 2). The difference is due to the susceptibility of prostigmatids and protura to desiccation during extraction. An important, though statistically insignificant trend, was for small-bodied, slow-moving groups to be underrepresented by direct observation. This is why astigmatid and oribatid mite density tended to be lower when observed directly than when soil extraction was used. Aggregations of the hypopae of astigmatid mite species and collembola were observed; direct observation offers a method to study this important phenomenon. 
August 1989

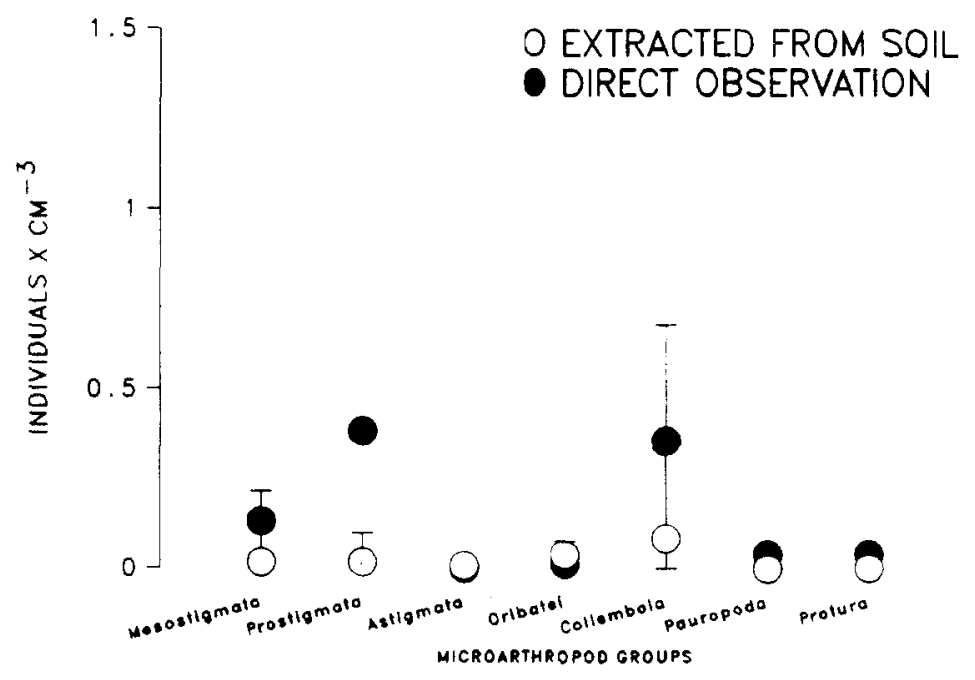

May 1991

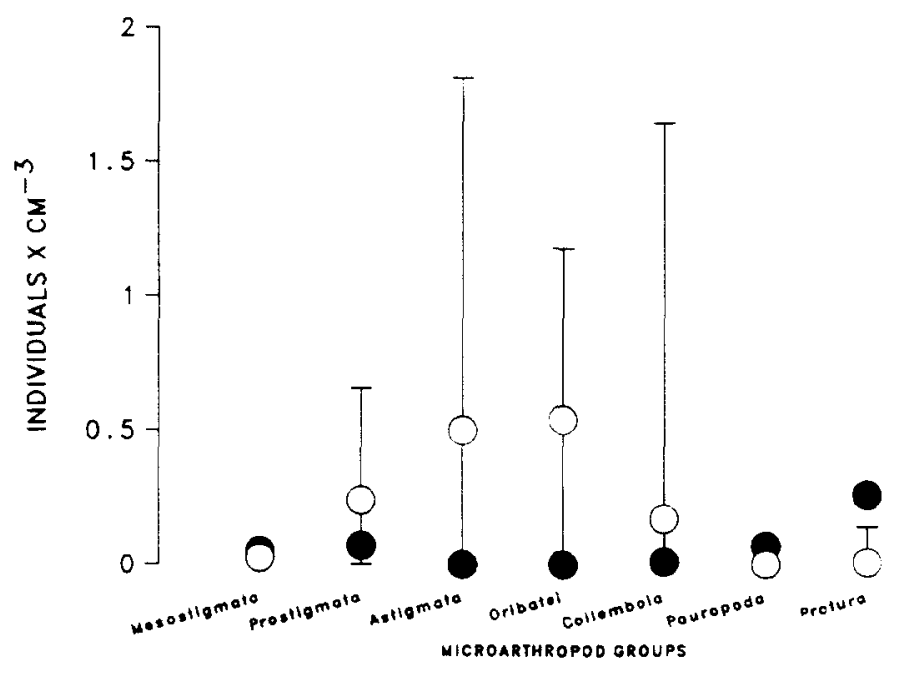

Fig. 2. Comparison of microarthropod density determined by direct observation of rhizotron windows with microarthropods extracted from soil cores collected next to rhizotron windows. Each point is the average of seven $172.5 \mathrm{~cm}^{3}$ cores for soil extraction $\pm 5 \%$ student $t$ confidence intervals and $759 \mathrm{~cm}^{3}$ and $138 \mathrm{~cm}^{3}$ sampled by direct observation in August 1989 and May 1991, respectively. 


\section{Density estimates from time-lapse video}

Invertebrates are infrequent in time lapse video recordings because the field of view is small, usually about $1 \mathrm{~cm}^{2}$. Overall, an average of 0.003 microarthropods per $\mathrm{cm}^{2}$ per 30 second interval were observed between July and November 1990 in the University of Michigan Soil Biotron. Further, microarthropods appear independently of one another. For these reasons the number of microarthropods per unit time fits the Poisson distribution, at least at the spatio-temporal scale of video recording (Table 1). This is useful because it suggests the appropriate tests for confidence limits and comparisons of means. Questions of ecological interest can also be answered using the fit of microarthropod appearances to the Poisson distribution. For example, the length of time a root surface is expected to be occupied by a microarthropod can be calculated.

An example of the use of time-lapse video to estimate microarthropod density is the five month time-lapse record shown in Fig. 1. The number of microarthropods observed per week rose twice, and declined in the fall. On the ten dates when the area of Coenococcum geophilum ectomycorrhizae was measured, microarthropod occurrence was negatively correlated with ectomycorrhizal area (Wilcoxon matched-pairs, signed-ranks test, $p<0.01$ ).

\section{Interactions among soil biota}

Herbivory and other plant-animal interactions are important enough aboveground to justify much space in general ecology texts. It is hard to imagine that interactions of invertebrates with roots, protozoa, and microorganisms is not just as important. The observations of interactions that have been made suggest the potential of in situ observation. For example, Linford (1939) demonstrated that nematodes are attracted to the extension zone of roots by using direct observation of roots growing against glass; time-lapse cinematog-

\section{TABLE 1}

Fit of microarthropod numbers in 30 second video records to the Poisson distribution

\begin{tabular}{|c|c|c|c|c|}
\hline \multirow{3}{*}{$\begin{array}{l}\text { Number of } \\
\text { microarthropods } \\
\text { per interval }\end{array}$} & \multicolumn{4}{|c|}{ Frequencies } \\
\hline & \multicolumn{2}{|c|}{ April 16-May 28, 1991} & \multicolumn{2}{|c|}{ June 25-Nov. 6, 1990} \\
\hline & Observed & Expected & Observed & Expected \\
\hline 0 & 912 & 912.4 & 1472 & 1472.8 \\
\hline 1 & 24 & 23.3 & 49 & 47.4 \\
\hline$>1$ & 0 & 0.3 & 0 & 0.8 \\
\hline Total & $\overline{936}$ & & $\overline{1521}$ & \\
\hline
\end{tabular}


raphy of the extension zone of apple roots in the East Malling Rhizotron was used to further study this attraction (Pitcher, 1967). The possibility that nematodes reduce contact between fruit tree roots and soil was raised by Atkinson and Wilson's (1979) observations in the East Malling rhizotron. For microarthropods, counts through windows of the University of Michigan Soil Biotron showed a density on tree roots two orders of magnitude greater than in the adjacent soil Lussenhop et al. (1990). With these exceptions, students of soil invertebrates have not used direct observation to study behavior or interactions with other biota.

\section{CONCLUSIONS}

In situ observation of the soil and its biota allows repetitive observations of spatio-temporal relationships. Visualization of soil processes will be aided by adaptation of laboratory techniques. Repetitive observation allows improved estimates of root and microbial turnover and productivity, which are relevant to global productivity and carbon balance. In addiition, minirhizotrons and rhizotrons allow observation of interactions between the soil biota. Interactions among the soil biota are likely to be at least as important to ecosystem functioning as above-ground interactions such as herbivory are. In short, now that we can see the soil biota in their natural setting, soils will be more a part of the ecosystem.

\section{ACKNOWLEDGEMENTS}

We thank James A. Teeri, Director of the University of Michigan Biological Station (UMBS) for support, and Robert Vande Kopple of UMBS for help in the Soil Biotron. Construction of the Soil Biotron was supported by a grant from the National Science Foundation (BSR-86-15565).

\section{REFERENCES}

Aerts, R., Berendse, F., Klerk, N.M. and Bakker, C., 1989. Root production and root turnover in two dominant species of wet heathlands. Oecologia, 81: 374-378.

Allen, M.F., Allen, E.B. and Friese, C.F. 1989. Responses of the non-mycotrophic plant Salsola kali to invasion by vesicular-arbuscular mycorrhizal fungi. New Phytol., 111: 45-49.

Ames, R.N., Ingham, E.R. and Reid, C.P.P., 1982. Ultraviolet-induced autofluorescence of arbuscular mycorrhizal root infections: an alternative to clearing and staining methods for assessing infections. Can. J. Microbiol., 28: 351-355.

Atkinson, D., 1985. Spatial and temporal aspects of root distribution as indicated by the use of a root observation laboratory. In: A.H. Fitter (Editors), Ecological Interactions in Soil. Blackwell, Oxford, pp. 43-65.

Atkinson, D. and Wilson, S.A., 1979. The root-soil interface and its significance for fruit tree 
roots of different ages. In: J.L. Harley and R.S. Russell (Editors), The Soil-Root Interface. Academic Press, London, pp. 259-271.

Box, J.E., Smucker, A.J.M. and Ritchie, J.T., 1989. Minirhizotron installation techniques for investigating root responses to drought and oxygen stresses. Soil Sci. Soc. Am. J., 53: $115-$ 118.

Caldwell, M.M., 1987. Competition between root systems in natural communities. In: P.J. Gregory, J.V. Lake and D.A. Rose (Editors), Root Development and Function. Cambridge Univ. Press, Cambridge, pp. 167-185.

Carpenter, A., 1988. The biology of Campodea staphylinus (Campodeidae: Diplura) in a grassland soil. Pedobiologia, 32: 31-38.

Carpenter, A., Cherrett, J.M., Ford, J.B., Thomas, M. and Evans, E., 1985. An inexpensive rhizotron for research on soil and litter-living organisms. In: A.H. Fitter (Editor), Ecological Interactions in Soil. Blackwell, Oxford, pp. 67-71.

Casida, L.E., 1969. Observations of microorganisms in soil and other natural habitats. Appl. Microbiol., 18: 1065-1071.

Cheng, W., Coleman, D.C. and Box, J.E., Jr., 1990. Root dynamics, production and distribution in agroecosystems on the Georgia piedmont using minirhizotrons. J. Appl. Ecol., 27: 592604.

Edwards, C.A. and Fletcher, K.E., 1971. A comparison of extraction methods for terrestrial arthropods. In: J. Phillipson (Editors), Methods of Study in Quantitative Soil Ecology. Blackwell, Oxford, pp. 150-185.

Fogel, R. and Lussenhop, J., 1991. The University of Michigan Soil Biotron: a platform for soil biology research in a natural forest. In: D. Atkinson (Editors), Plant Root Systems: Their Effect on Ecosystem Composition and Structure. Blackwell, Oxford, pp. 61-68.

Gijsman, A.J., Floris, J., Van Noordwijk, M. and Brouwer, G., 1991. An inflatable minirhizotron system for root observations with improved soil/tube contact. Plant Soil, 134:261-269.

Hansson, A.C. and Andren, O., 1987. Root dynamics in barley, lucerne and meadow fescue investigated with a mini-rhizotron technique. Plant Soil, 103: 33-38.

Hendrick, R.L. and Pregitzer, K.S., 1992. The demography of fine roots in a northern hardwood forest. Ecology, 73: 73: 1094-1104.

Hole, F.D., 1981. Effects of animals on soil. Geoderma, 25: 75-112.

Huck, M.G. and Taylor, H.M., 1982. The rhizotron as a tool for root research. Adv. Agron., 35: $1-35$.

Jarnagin, J.L. and Luchsinger, D.W., 1980. The use of fluorescein diacetate and ethidium bromide as a stain for evaluating viability of mycobacteria. Stain Technol., 55: 253-258.

Kubiëna, W., 1955. Animal activity in soils as a decisive factor in establishment of humus forms. In: D. Kevan (Editor), Soil Zoology. Butterworths, New York, pp. 73-82.

Linford, M.B., 1939. Attractivness of roots and excised shoot tissues to certain nematodes. Proc. Helminthol. Soc. Wash., 6: 11-18.

Long, S.P., Garcia Moya, E., Imbamba, S.K., Kamnalrut, A., Piedade, M.T.F., Scurlock, J.M.O., Shen, Y.K. and Hall, D.O., 1989. Primary productivity of natural grass ecosystems of the tropics: a reappraisal. Plant Soil, 115: 155-166.

Lussenhop, J., 1971. A simplified canister-type soil arthropod extractor. Pedobiologia, 11: 4045.

Lussenhop, J., Fogel, R. and Pregitzer, K., 1990. A new dawn for soil biology: video anlaysis of root-soil-microbial-faunal interactions. Agric. Ecosyst. Environ., 34: 235-249.

MacDonald, R.M., 1980. Cytochemical demonstration of catabolism in soil microorganisms. Soil Biol. Biochem., 12: 419-423.

Pitcher, R.S., 1967. The host-parasite relations and ecology of Trichodorus viruliferous on apple roots as observed from an underground laboratory. Nematologica, 13: 547-567.

Roser, D.J., 1980. Ethidium bromide: a general purpose fluorescent stain for nucleic acid in 
bacteria and eucaryotes and its use in microbial ecology studies. Soil Biol. Biochem., 12: 329-336.

Rush, C.M., Upchurch, D.R. and Gerik, T.J., 1984. In situ observations of Phymatotrichum omnivorum with a borescope mini-rhizotron system. Phytopathology, 74: 104-105.

Snider, R.J., Snider, R. and Smucker, A.J.M., 1990. Collembolan populations and root dynamics in Michigan agroecosystems. In: J.E. Box and L.C. Hammond (Editors), Rhizoplane Dynamics. Westview, Boulder, CO, pp. 168-191.

Söderström, B.E., 1977. Vital staining of fungi in pure cultures and in soil with fluorescein diacetate. Soil Biol. Biochem., 9: 59-63.

Sylvia, D.M., 1988. Activity of external hyphae of vesicular-arbuscular mycorrhizal fungi. Soil Biol. Biochem., 20: 39-43.

Van Noordwijk, M., De Jager, A. and Floris, J. 1985. A new dimension to observations in minirhizotrons: a stereoscopic view on root photographs. Plant Soil, 86: 447-453.

Vos, J. and Groenwold, J., 1987. The relation between root growth along observation tubes and in bulk soil. In: H.M. Taylor (Editor), Minirhizotron Observation Tubes: Methods and Applications for Measuring Rhizosphere Dynamics. Am. Soc. of Agronomy, Madison. WI, pp. $39-49$. 